\title{
Updating reliability of steel miter gates on locks and dams using visual inspection results
}

\author{
Allen C. Estes $^{\mathrm{a}, *}$, Dan M. Frangopol ${ }^{\mathrm{b}}$, Stuart D. Foltz ${ }^{\mathrm{c}}$ \\ ${ }^{a}$ Department of Civil and Mechanical Engineering, United States Military Academy, West Point, NY 10996, USA \\ ${ }^{\mathrm{b}}$ Department of Civil, Environmental, and Architectural Engineering, University of Colorado, Boulder, CO 80309-0428, USA \\ ${ }^{\mathrm{c}}$ US Army Construction Engineering Laboratory, Champaign, IL 61826, USA
}

\begin{abstract}
As both reliability analyses and systematic inspection programs for the world's infrastructure gain increased usage and prominence, it becomes more important to use the information from routine visual inspections to update lifetime reliability assessments and resulting life-cycle inspection/repair strategies. The Army Corps of Engineers currently uses reliability analyses to economically justify the major rehabilitation of navigation structures. This paper illustrates how the Condition Index visual inspections for locks and dams can be modified and used to update the reliability analysis of a steel miter gate. The miter gates on two existing locks and dams along the Mississippi River are used as examples for corrosion and fatigue deterioration. The approach used is applicable to any structure where the inspection condition states are quantitative and a model exists to relate visual inspection results to the actual deterioration state of the structure.
\end{abstract}

Keywords: Condition states; Limit states; Miter gates; Locks; Deterioration models; Structural reliability; Inspection; Corrosion; Fatigue cracks; Bayesian updating

\section{Introduction}

While the acceptance of reliability-based analysis and design methods is gaining increased usage and prominence, the US Army Corps of Engineers (USACE) stands out as one of the few organizations that are using such methods to make real economic decisions on the life-cycle management of infrastructure. A timedependent reliability analysis is critical for maintenance planning and is a mandatory step in justifying a major rehabilitation project. Such a project involves structural work on a USACE operated and maintained facility such as a lock, dam, or hydropower plant (typically, involving a cost of over US\$ 8 million) where the project will improve the reliability of the structure and will defer the cost of its replacement [23]. Structural safety analysts compute the reliability of various structures at

\footnotetext{
* Corresponding author. Tel.: +1-845-938-4607; fax: +1-845-9385522.

E-mail address: ia2804@exmail.usma.edu (A.C. Estes).
}

specific points in time based on the randomness of the demand, the structural capacity, and the projected deterioration. These points in time reliabilities are transformed to a probability density function (PDF) for the time to failure. The PDF is converted to a hazard function that is provided to the economists, who use a probability tree of likely failure events and a cost-benefit analysis to determine if the major rehabilitation is economically justified.

A time-dependent reliability analysis for a structure requires a number of assumptions about the loading, resistance, and deterioration models. The model is usually derived theoretically, obtained from laboratory data, or interpolated from the behavior of similar structures under similar conditions. These models predict future performance over several decades and are the basis for optimum life-cycle inspection and repair planning. To be effective, these models must be updated over time to revise the maintenance strategy based on how a structure actually behaves. The best sources of data are specific non-destructive evaluations (NDEs) 
taken at optimum time intervals. Unfortunately, such NDE inspections are often expensive and not available for every structure.

Regular visual inspections have become commonplace for many structures where standard data are collected, entered into a database, and used to prioritize maintenance needs. These activities require inspectors to translate their observations into pre-defined condition states. As the US has invested billions of dollars in civil infrastructure, the cost associated with the collapse of even one major bridge, offshore oil platform, or skyscraper is huge in terms of monetary damage, loss of life, and erosion of public trust and confidence. As such, the managers of such facilities (often the government) have mandated and implemented these inspection programs that typically require a periodic and standardized inspection to be performed on all structures. The Federal Highway Administration, for example, requires that all highway bridges in the National Bridge Inventory be inspected every two years [7]. The Corps of Engineers uses a condition index (CI) inspection and rating system on its locks and dams along the nation's navigable rivers [20].

At first glance, it would appear that these visual inspections would be of little use in updating the reliability of a structure - they were not designed for this purpose. However, with some conservative assumptions and quantitative definitions of the condition states, the information can be useful for reliability purposes. The question is not whether these visual inspections can replace a targeted NDE inspection; they cannot. The question is whether this information can be used as an improvement to no information at all - and if so, how do we make the best use of such information? Estes and Frangopol [6] demonstrated how the condition state information from the PONTIS Bridge Management System visual inspections can be modified and used to update the reliability of highway bridges. This paper addresses to what extent the USACE periodic visual CI inspections can be used to update the reliability of miter gates on navigational locks.

\section{General approach}

Estes et al. [5] proposed a general approach for using visual inspection information to update the reliability of any type of structure. The process starts with the inspector observing the condition of a structure and choosing the most appropriate rating described in a standardized inspection guide. To use this information to update a reliability analysis, one must:

- Ensure that the classification is sufficiently described in quantifiable terms such as crack width, section loss, percentage spalls, etc. Revise the condition state definition if necessary.

- Define the condition state in probabilistic terms. Some conservative assumptions may be needed to achieve this.

- Relate what the inspector is observing to the specific deterioration being updated. This is easy if the defect is being observed directly and more difficult if the defect cannot be seen.

- Update the deterioration model based on the new information. Because there can be a high degree of uncertainty associated with both the prior deterioration and the visual inspection results, a Bayesian approach to updating is necessary.

- Update the reliability of the structure.

\section{Miter gates}

Miter gates provide the damming surface on a standard lock chamber. These welded steel gates are opened and closed to change the water elevation in the lock chamber, which allows navigation traffic to gently travel up- and downriver. USACE maintains 238 lock chambers at 198 lock sites throughout the US. In many situations, only one lock is available at a site and if the miter gate does not function, navigation along the entire river is delayed. A typical miter gate consists of supporting girders (framed in either the horizontal or vertical direction) and intercostals (diaphragms) that are perpendicular to the girders and are designed as fixed end beams. A skin plate covers this grid-like structure and holds back the water on the upstream side. The gates swing about their supports at the concrete chamber wall and meet at an angle of about $30^{\circ}$ when closed or mitered. Miter gates are designed to resist the repeated hydrostatic loads produced by changing water elevation [22]. Two specific miter gates from Locks and Dams 12 and 27 along the Mississippi River (Fig. 1) will be used as illustrative examples where the relevant deterioration mechanisms are corrosion and fatigue, respectively. Each case study will introduce the reliability analysis methodology and results, explain the visual inspection as it is currently prescribed, and then follow the general approach listed above to use the inspection results to update the reliability analysis.

\section{Reliability analysis of Lock and Dam 12}

The Rock Island District of the USACE prepared a time-dependent reliability analysis of Lock and Dam 12 (Fig. 2) on the Mississippi River near Dubuque, IA, to predict how this structure will perform over its useful life [24]. This gate comprises vertically framed girders similar to those shown in Fig. 3. The reliability 


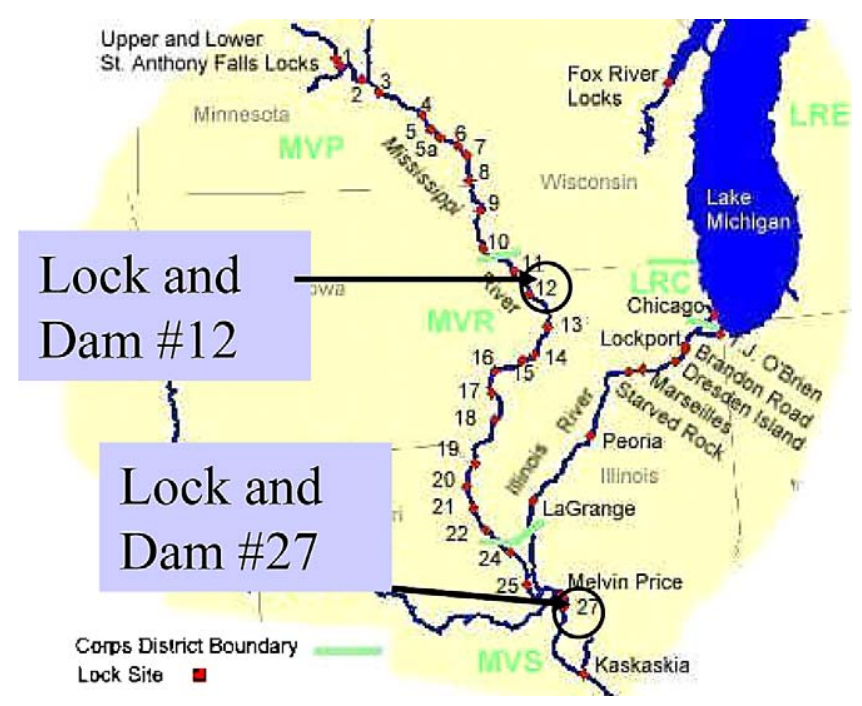

Fig. 1. Locations of US Army Corps of Engineers Locks and Dams 12 and 27.

analysis was based on the bending failure limit state of a typical vertical girder. The hydrostatic forces on the girder from the upstream and downstream water levels and the resulting moment diagram are shown in Fig. 4. The maximum moment $\left(M_{\max }\right)$ varies as the level of water in the lock chamber rises and falls. All interior girders experience the same hydrostatic loading.

The elastic bending stress equation is used to determine the actual stress $\left(F_{\text {act }}\right)$ in the vertical girder:

$F_{\mathrm{act}}=\frac{M_{\mathrm{max}} y_{\mathrm{NA}} k_{\mathrm{s}}}{I_{\mathrm{NA}}}$

where $y_{\mathrm{NA}}$ and $I_{\mathrm{NA}}$ are the distance to and the moment of inertia about the neutral axis of the composite crosssection of the girder and skin plate. The random stress uncertainty factor $k_{\mathrm{s}}$ is assumed lognormally distributed, LN $[0.96,0.12]$, which indicates a mean value

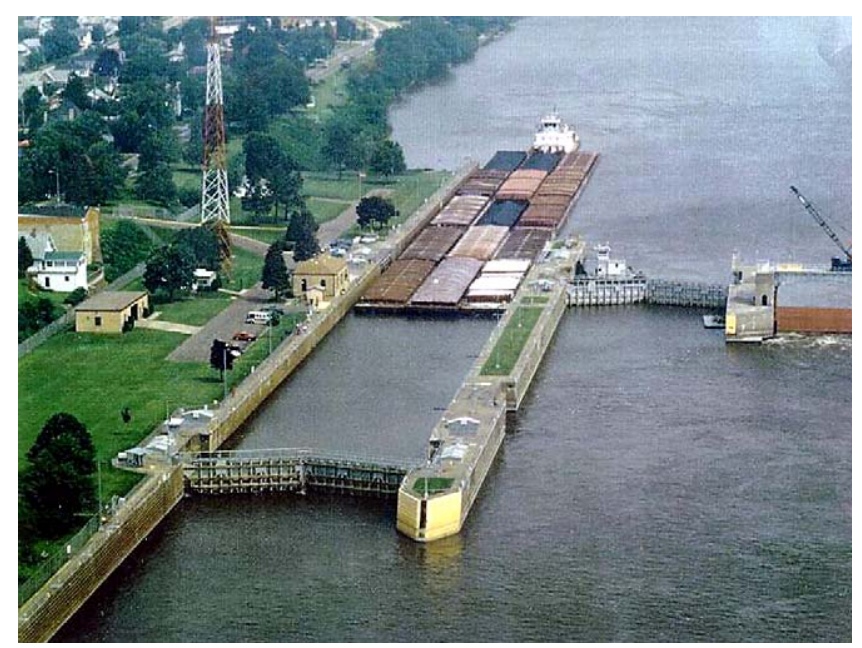

Fig. 2. Photograph of Lock and Dam 12 [27].

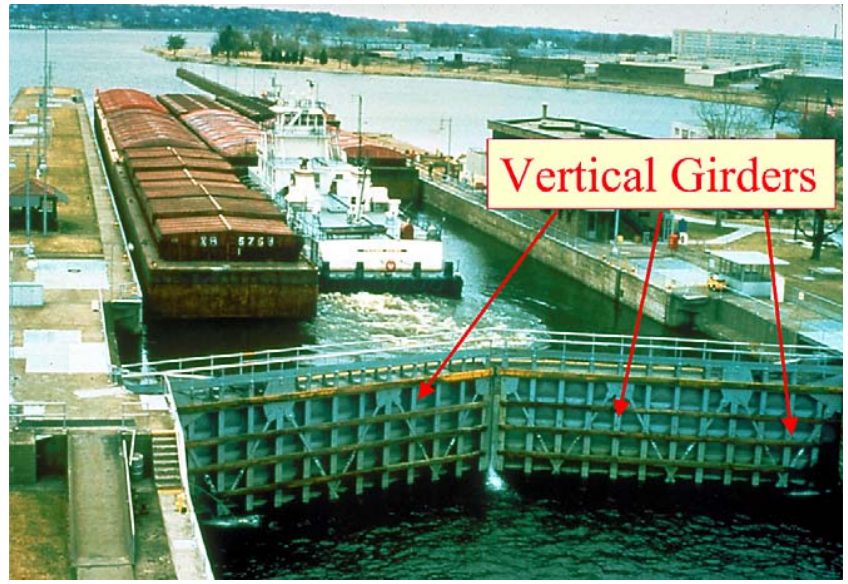

Fig. 3. Typical vertically framed miter gate $[4,27]$.

of $\mu=0.96$ and a standard deviation of $\sigma=0.12$ [16]. This value was determined by comparing the theoretical strains following the design model assumptions with actual strain gage data from various girders. The other random variables considered in the analysis are shown in Table 1.

The pool elevations are used to compute $M_{\max }$. The miter gate reliability is defined as the probability that the structure survives, $\operatorname{Pr}\left(F_{\text {act }}<F_{\mathrm{y}}\right)$, where $F_{\mathrm{y}}$ is the yield stress of the steel.

Corrosion deterioration was considered in both the splash and atmospheric zones of the miter gate. This gate is usually divided into three environmental zones: the atmospheric zone, where the gate is only exposed to air, the splash zone, where the gate is exposed to both water and air as the water in the chamber is raised and lowered, and the submerged zone, where the gate remains constantly underwater. Based on results from corrosion tests of bare steel under simulated splash-zone conditions conducted in Memphis [21] and

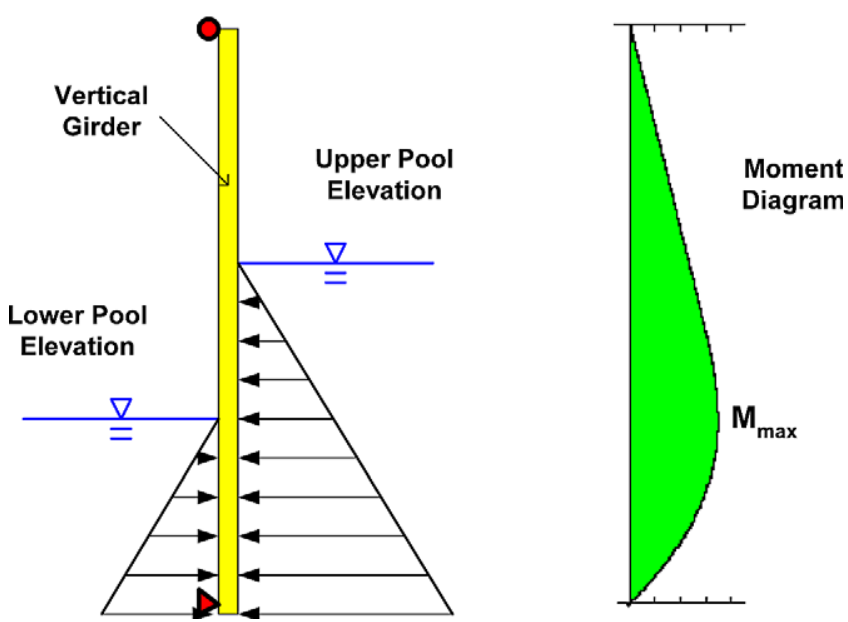

Fig. 4. Hydrostatic forces and resulting moment diagram on a vertically framed miter gate girder. 
Table 1

Random variables used in reliability analysis of vertical girders on Lock and Dam 12 [16,24]

\begin{tabular}{lllll}
\hline Random variable & Symbol & Distribution type & Mean $(\mu)$ & Standard deviation $(\sigma)$ \\
\hline Minimum lower pool elevation & $\mathrm{El}_{\text {lower-min }}$ & Normal & $177.90 \mathrm{~m}(583.67 \mathrm{ft})$ & $0.23 \mathrm{~m}(0.74 \mathrm{ft})$ \\
Yield stress of steel & $F_{\mathrm{y}}$ & Normal & $245.7 \mathrm{MPa}(35.64 \mathrm{ksi})$ & $31.8 \mathrm{MPa}(4.62 \mathrm{ksi})$ \\
Stress model uncertainty factor & $k_{\mathrm{s}}$ & Lognormal & 0.96 & 0.12 \\
Corrosion uncertainty factor for atmospheric zone & $\varepsilon_{\mathrm{c}-\text { atmos }}$ & Normal & 0.0 & 0.219 \\
Corrosion uncertainty factor for splash zone & $\varepsilon_{\mathrm{c}-\text { splash }}$ & Normal & 0.0 & 0.099 \\
\hline
\end{tabular}

tests on steel coupons in a variety of environments [1], the following deterioration models were derived for the atmospheric and splash zones [16]:

$\log C=\log 23.4+0.65 \log t+\varepsilon_{\mathrm{c}}$

$\log C=\log 148.5+0.903 \log t+\varepsilon_{\mathrm{c}}$

respectively, where $C$ is the thickness loss due to corrosion in micrometers, $t$ is time in years, and $\varepsilon_{\mathrm{c}}$ is an uncertainty factor with a mean of 0 and standard deviations of 0.219 and 0.099 for the atmospheric and splash zones, respectively. Fig. 5 shows how the thickness loss due to corrosion reduces the girder crosssection, where $A_{1}, \ldots, A_{4}$ are the separate areas of the composite cross-section and $y_{1}, \ldots, y_{4}$ are the distances to the centroids of those areas. The miter gate was put into service in 1938 and was treated with a coal-tar epoxy paint that was assumed to last for 10 years. Structural performance was forecasted to the year 2030. The section loss causes the actual stress in the girder to increase and Fig. 6 illustrates how the probability of failure is increased over time as it becomes increasingly likely that $F_{\mathrm{a}}>F_{\mathrm{y}}$. With this information, the future performance of the miter gate was estimated using time-dependent reliability, hazard functions, and an event tree to compute the expected costs of disruptions.

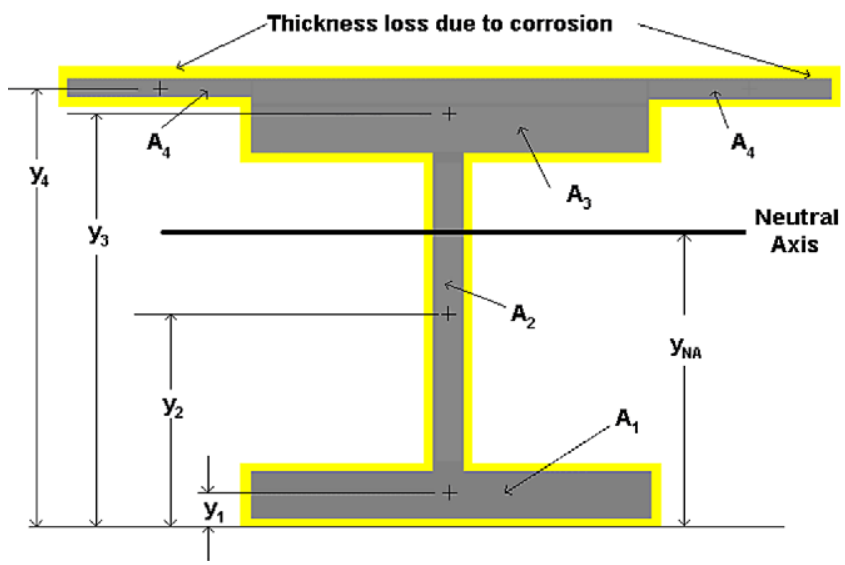

Fig. 5. Thickness loss due to corrosion on composite cross-section of the vertical girder.

\section{Condition index inspections}

The reliability analysis on Lock and Dam 12 extends over nine decades. The analysis needs to be updated over time based on inspection results to verify or modify the deterioration model on which it was based. Ideally, a specific NDE would provide the basis for updating the parameters of the random variable that accounts for thickness loss due to corrosion. NDE tests are often expensive and are not routinely conducted.

The USACE Repair, Maintenance, and Rehabilitation (REMR) program attempts to efficiently maintain existing civil works structures and build baseline data to monitor deterioration rates. A detailed inspection and rating program has been established for steel sheet pile structures, miter gate lock structures, sector gates, tainter and butterfly valves, and tainter dam and lock gates [20]. The result of these inspections is a CI rating for individual structures between 0 and 100 that describes the current state of the operating equipment as shown in Table 2 ([9]).

A CI inspection is conducted periodically as part of a program of visual inspections to assess the general condition of a miter gate. The CI ratings are used to help prioritize maintenance. While these inspections were not specifically designed for updating the

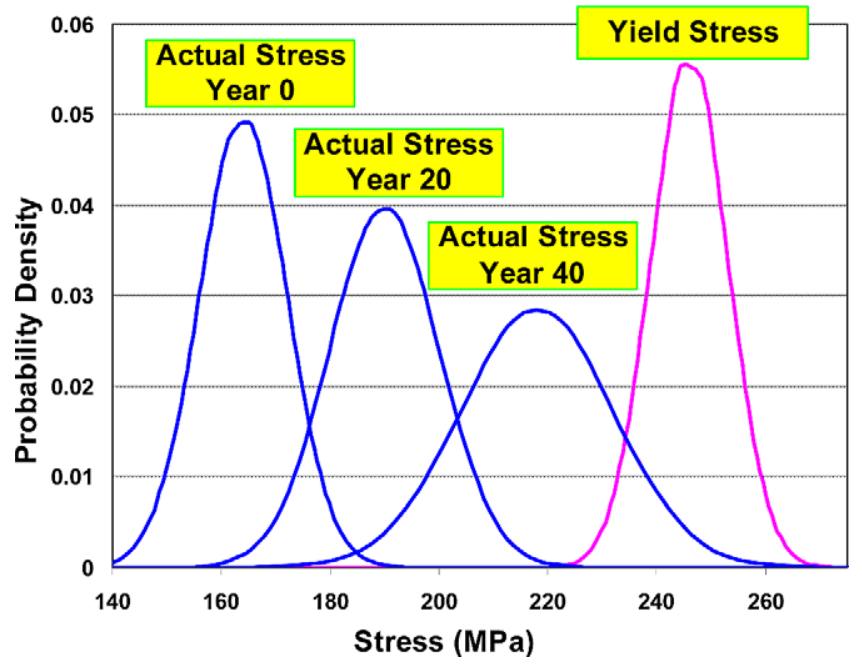

Fig. 6. Decrease in reliability over time as reduced section loss causes an increase in the bending stress on the girders. 
Table 2

Condition index rating scale for inspected structures [9]

\begin{tabular}{|c|c|c|c|}
\hline CI value & Condition description & Zone & Action \\
\hline $\begin{array}{l}85-100 \\
70-84\end{array}$ & $\begin{array}{l}\text { Excellent: no noticeable defects; some aging or wear visible } \\
\text { Very good: only minor deterioration or defects evident }\end{array}$ & 1 & Immediate action not required \\
\hline $\begin{array}{l}55-69 \\
40-54\end{array}$ & $\begin{array}{l}\text { Good: some deterioration or defects evident; function not impaired } \\
\text { Fair: moderate deterioration; function is still adequate }\end{array}$ & 2 & $\begin{array}{l}\text { Economic analysis of repair alternatives } \\
\text { recommended to determine appropriate } \\
\text { maintenance action }\end{array}$ \\
\hline $\begin{array}{l}25-39 \\
10-24 \\
0-10\end{array}$ & $\begin{array}{l}\text { Poor: serious deterioration in at least some portions of the structure; function } \\
\text { inadequate } \\
\text { Very poor: extensive deterioration, barely functional } \\
\text { Failed: general failure or failure of a major component; no longer functional }\end{array}$ & 3 & $\begin{array}{l}\text { Detailed evaluation required to determine } \\
\text { the need for repair, rehabilitation or } \\
\text { reconstruction, safety evaluation required }\end{array}$ \\
\hline
\end{tabular}

reliability of a structure, they can be used conservatively for this purpose in some cases with some minor modification.

The CI inspection conducted on the miter gates on Lock and Dam 12 [25] provided a subrating for a variety of defects that include miter offset, bearing gaps, cracks, leaks, dents, anchorage movement, and corrosion. The $\mathrm{CI}$ inspection addresses corrosion in the splash zone and assigns a resulting functional $\mathrm{CI}$ where $\mathrm{CI}=100(0.4)^{X / X_{\max }}$ and $X$ is the measurement which quantifies an observed distress and $X_{\max }$ is the upper bound of $X$. The observed distress is the amount of corrosion on the girders, intercostals, and skin plates which are rated as $0-5$ with descriptions provided in Table 3.

The inspector matches the observed corrosion to pictures which illustrate levels $1-5$ to categorize the intensity of corrosion. Because the girders (G) are more critical structural members than the intercostals (I) or the skin plate $(\mathrm{S})$, the limiting value on the girders is $X_{\max \mathrm{G}}=3$, while for the other members, $X_{\max \mathrm{I}}=4$ and $X_{\max \mathrm{S}}=4$. Both the upstream (U) and downstream (D) sides are classified, where $\mathrm{CI}_{\mathrm{G}}=\min \left(\mathrm{CI}_{\mathrm{DG}}\right.$, $\left.\mathrm{CI}_{\mathrm{UG}}\right), \mathrm{CI}_{\mathrm{S}}=\min \left(\mathrm{CI}_{\mathrm{DS}}, \mathrm{CI}_{\mathrm{US}}\right), \mathrm{CI}_{\mathrm{I}}=\min \left(\mathrm{CI}_{\mathrm{DI}}, \mathrm{CI}_{\mathrm{UI}}\right)$, and $\mathrm{CI}=\min \left(\mathrm{CI}_{\mathrm{G}}, \mathrm{CI}_{\mathrm{S}}, \mathrm{CI}_{\mathrm{I}}\right)$. The corrosion results for CI inspection conducted in November 1998 for the auxiliary gate on Lock and Dam 12 are shown in
Table 4 [25]. The CI was $\mathrm{CI}=54$ based on the girder classifications where $\mathrm{CI}_{\mathrm{UG}}=\mathrm{CI}_{\mathrm{DG}}=100(0.4)^{2 / 3}=54$.

By itself, this information is not sufficient to update the reliability analysis. The limitations of the CI inspection data are:

- The amount of corrosion loss has not been numerically quantified and cannot be used to update a random variable in its current form.

- The CI inspection was only conducted for the splash-zone area, while reliability was assessed in both the splash zone and atmospheric zone.

- The CI rating was based on the worst condition observed anywhere on the gate. The analyst does not know on which member or where on the member the corrosion occurs. It is also unknown whether the rating is representative of the entire gate or one isolated section.

- There is no knowledge of condition state transition or how long the miter gate has been and will be in that condition state.

\section{Condition state definition for miter gate corrosion updating}

The inspector of a miter gate for a lock and dam received both a verbal description of the degree of section loss on a corroding girder or skin plate and a

Table 3

Conditions state definitions for corrosion levels for a condition index inspection [9]

\begin{tabular}{lllll}
\hline Rating & Description & \multicolumn{2}{l}{ Thickness loss per side } \\
\cline { 3 - 4 } & & mils & $\mu \mathrm{m}$ & Distribution $(\mu \mathrm{m})^{\mathrm{b}}$ \\
\hline 0 & New condition & 0 & 0 & - \\
1 & Minor surface scale or widely scattered small pits & $0-8$ & $0-200$ & $\mathrm{LN}[100,51]$ \\
2 & Considerable surface scale and/or moderate pitting & $0-20$ & $0-500$ & $\mathrm{LN}[250,128]$ \\
3 & Severe pitting in dense pattern, thickness reduction in local areas & $0-40$ & $0-1000$ & $\mathrm{LN}[500,255]$ \\
4 & Obvious uniform thickness reduction & $40-120$ & $1000-3000$ & $\mathrm{~N}[2000,510]$ \\
5 & Holes due to thickness reduction and general thickness reduction & $>120$ & $>3000$ & $\mathrm{~N}[4500,1531]$ \\
\hline
\end{tabular}

${ }^{\text {a }}$ Not currently in CI manual - created to quantify corrosion distress.

${ }^{\mathrm{b}}$ Based on very experienced inspector (when structure is in middle of condition state, will identify correct condition state $95 \%$ of the time). 
Table 4

Inspection results from auxiliary miter gate on Lock and Dam 12 [25]

\begin{tabular}{llllll}
\hline \multirow{2}{*}{$\begin{array}{l}\text { Structural } \\
\text { element }\end{array}$} & \multicolumn{2}{l}{ Left leaf } & & & Right leaf \\
\cline { 2 - 3 } \cline { 5 - 5 } \cline { 5 - 5 } & Upstream & Downstream & & Upstream & Downstream \\
\hline Girder & 2 & 2 & 1 & 2 \\
Intercostal & 2 & 2 & 1 & 2 \\
Skin plate & 2 & 2 & 1 & 2 \\
\hline
\end{tabular}

photograph that matched the description [9]. Based on that information, the condition state is quantified in terms of the relative section loss as shown in Table 3.

To define the condition states in probabilistic terms, it was assumed that condition state deterioration over time is linear and the deterioration intensity is normally or lognormally distributed. To ensure the model is conservative, it is also assumed that a miter gate element is initially at the half-way point of a specific condition state and progressively shifts over time. The standard deviation of the distribution is determined by the quality of the inspection program. The study considered three possible inspection programs where the inspectors were categorized as very experienced, experienced, and inexperienced and the correct condition state ratings could be expected $95 \%, 85 \%$, and $75 \%$ of the time, respectively. The quality of the inspection program was determined using seven criteria that include presence of a quality assurance inspector to verify field reports, number of years experience of inspectors, and a formal certification program [6]. The probabilistic definitions for the condition states when first entered using a very experienced inspector are shown in Fig. 7. For each condition state, the mean value was the midpoint of the condition state range (Table 3) and the standard deviation was based on the quality of the inspection program and the assumed percentage of time the inspector makes the correct classification.

Four separate methods are considered for using this CI inspection data to update the reliability analysis for a miter gate. Method $\mathrm{A}$ is the simplest and was

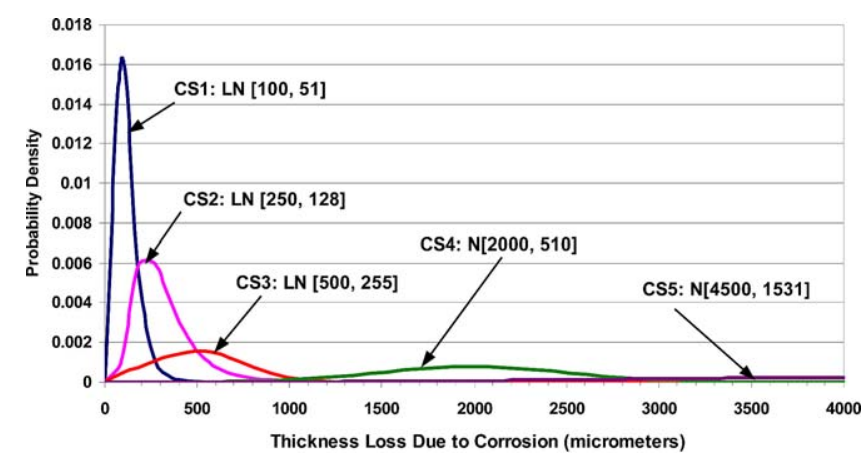

Fig. 7. Condition state distribution for section loss due to corrosion (very experienced inspector). described above. Methods B-D involve using Bayesian updating, a segment-based inspection, and the combination of both, respectively.

\section{Bayesian updating}

Bayesian updating techniques are very useful when faced with two sets of uncertain information and a planner needs to know which to believe. Bayesian updating uses both the prior information and new inspection information to account for the relative uncertainty associated with these types of information.

Assume that prior to an inspection, a random variable $\Theta$ was believed to have a density function $f^{\prime}(\Theta)$, where $\Theta$ is the parameter of that distribution (i.e., the deterioration model). During an inspection, a set of values $x_{1}, x_{2}, \ldots, x_{n}$ representing a random sample from a population $X$ with underlying density function $f(x)$ are observed and are fit to a new density function $f\left(x_{i}\right)$ (i.e., the visual inspection results). The updated or posterior density function $f^{\prime \prime}(\Theta)$ which uses both sets of information and provides the best use of both can be expressed as [2]

$f^{\prime \prime}(\Theta)=k L(\Theta) f^{\prime}(\Theta)$

where $L(\Theta)$ is a likelihood function and $k$ is a normalizing constant. For the case where both $f^{\prime}(\Theta)$ and $f(x)$ are normally distributed, the posterior function $f^{\prime \prime}(\Theta)$ is also normally distributed and has the mean value and standard deviation, respectively, as

$\mu^{\prime \prime}=\frac{\mu\left(\sigma^{\prime}\right)^{2}+\mu^{\prime}(\sigma)^{2}}{\left(\sigma^{\prime}\right)^{2}+(\sigma)^{2}}$ and $\sigma^{\prime \prime}=\sqrt{\frac{\left(\sigma^{\prime}\right)^{2}(\sigma)^{2}}{\left(\sigma^{\prime}\right)^{2}+(\sigma)^{2}}}($

where $\mu, \mu^{\prime}$ and $\mu^{\prime \prime}$ represent the mean values of the inspection results, the prior distribution, and the posterior distribution, respectively. The values $\sigma, \sigma^{\prime}$, and $\sigma^{\prime \prime}$ represent the standard deviations of those same distributions. Fig. 8 shows the prior, inspection, and posterior distributions for the inspection results shown in Table 4 for both the splash zone and atmospheric zone. Because of the high degree of corrosion expected in the splash zone in 1998 and its associated uncertainty, the effect of the inspection results dominated the posterior distribution. The projected deterioration and its uncertainty were much less in the atmospheric zone. The deterioration model and the inspection results received about equal weight in computing the posterior distribution.

\section{Segment-based inspection}

A segment-based inspection is introduced where each girder, skin plate, and intercostal section is given its own rating in the same manner as suggested by Renn 

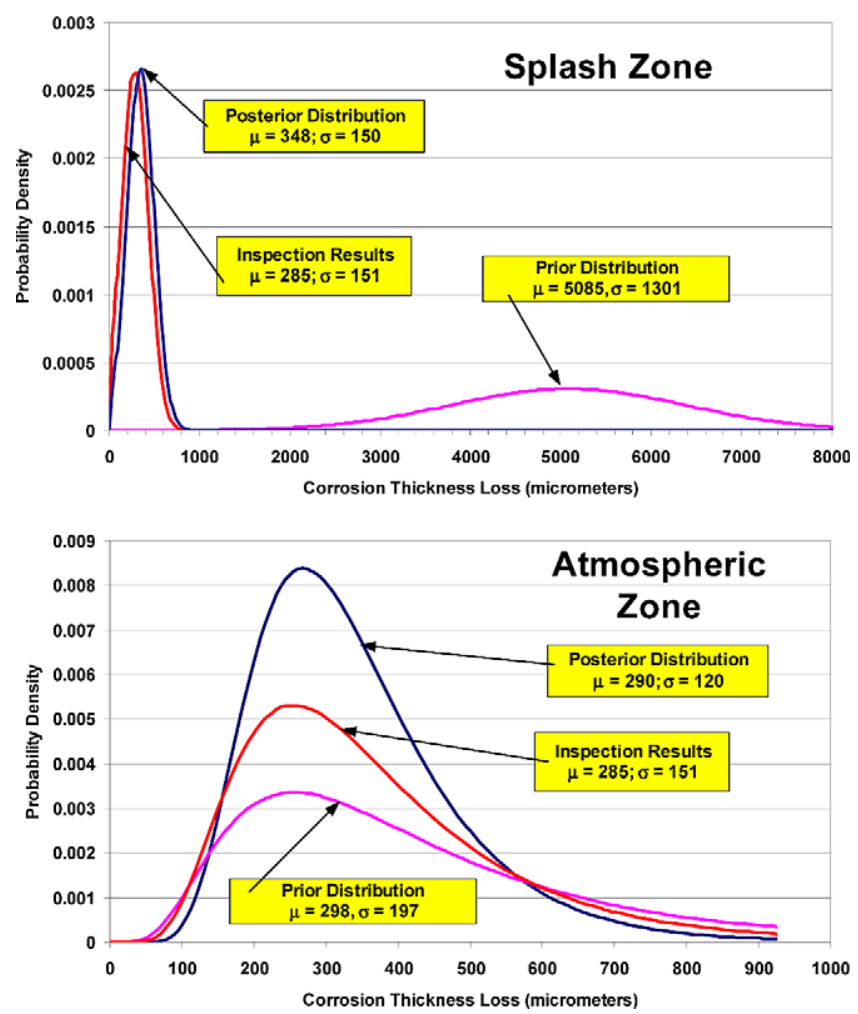

Fig. 8. Bayesian updating based on inspection results for the atmospheric and splash zones.

[19] and Hearn and Frangopol [10] for highway bridges. When each segment receives a rating, a composite or weighted average rating for the structure is possible which provides more information about the location and extent of damage. As CI inspections are conducted over time, a segment-based inspection provides better information about how the structure is transitioning through the condition state. It allows consideration of other failure modes where the location of the damage is important. Finally, a miter gate is a highly redundant structure that could quite conceivably be modeled as a series-parallel type system. A system reliability update based on CI inspection information would be impossible without a segment-based inspection where the condition of the individual members would be needed.

A segment-based inspection requires additional work in the preparatory phase, but does not take longer to conduct. Even when inspection results are based on a worst-case rating, every member must still be examined. It does not require much additional effort to record that rating. Since a miter gate is naturally divided into identifiable segments by the girders and intercostals, it lends itself well to a segment-based inspection. Hypothetical segment-based inspection results for a portion of upstream gate for Lock and Dam 12 are shown in Fig. 9 where the miter gate rating is recorded

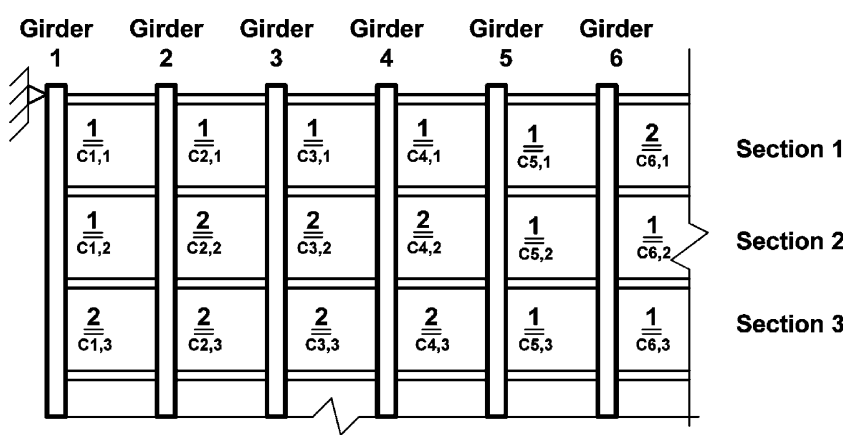

Fig. 9. Segment-based inspection for corrosion deterioration.

on a picture and the miter gate is subdivided and evaluated by specific numbered sections. An alternative and simpler format is illustrated in Table 5 for the entire gate structure where the evaluation is tabular and sections are represented by the environmental zones.

\section{Miter gate corrosion updating}

Table 6 shows the thickness loss predicted by the reliability analysis deterioration models in both the atmospheric zone (Eq. (2)) and the splash zone (Eq. (3)) as well as the updated thickness loss using all four methods based on 1998 inspection data. The results indicate that the model used for the atmospheric zone offers a good representation of what is actually happening in the splash zone. The splash-zone model greatly overestimates the severity of the corrosion. For methods $\mathrm{A}$ and $\mathrm{C}$, the actual inspection data (Table 4) were used, while for methods $\mathrm{B}$ and $\mathrm{D}$, the data were created from a hypothetical segment-based inspection by filling in the gaps based on the actual inspection data. Table 7 outlines the characteristics, requirements, and capabilities of the four methods.

Using method D which requires both a segmentbased inspection and Bayesian updating, the deterioration model was updated based on a hypothetical segment-based inspection in the year 2008. Fig. 10 shows the distribution of the thickness loss for condition state 2 (from Table 3) based on the results of the segmentbased inspections. The graphs show the computed distribution when the structure first enters the condition state 2 (it is conservatively assumed that the condition state is entered at the half-way point; i.e., $\mu=250 \mu \mathrm{m}$ ), at the year 1998, and at the year 2008. The mean value could go as high as $500 \mu \mathrm{m}$ where it would remain until an inspector classified the damage as condition state 3 [3]. After the inspections in 1998 and 2008, the deterioration model was updated based on the prior and new information. The new models, as shown in Fig. 11, are expressed as $C=10.23 t^{0.903}$ and $C=$ 
Table 5

Alternative format for a segment-based inspection on Lock and Dam 12 for corrosion deterioration

\begin{tabular}{|c|c|c|c|c|c|c|}
\hline \multirow[t]{2}{*}{ Girder } & \multicolumn{3}{|l|}{ Left-hand gate } & \multicolumn{3}{|l|}{ Right-hand gate } \\
\hline & Atmospheric zone & Splash zone & Submerged zone & Atmospheric zone & Splash zone & Submerged zone \\
\hline \multicolumn{7}{|c|}{ Upstream gate } \\
\hline 1 & 1 & 1 & 1 & 2 & 2 & 1 \\
\hline 2 & 1 & 2 & 1 & 2 & 2 & 1 \\
\hline 3 & 2 & 2 & 1 & 1 & 2 & 1 \\
\hline 4 & 2 & 2 & 1 & 1 & 2 & 1 \\
\hline 5 & 1 & 2 & 1 & 1 & 2 & 1 \\
\hline 6 & 1 & 2 & 1 & 2 & 2 & 1 \\
\hline 7 & 1 & 2 & 1 & 1 & 2 & 1 \\
\hline 8 & 1 & 2 & 1 & 2 & 2 & 1 \\
\hline 9 & 2 & 2 & 1 & 1 & 1 & 1 \\
\hline 10 & 2 & 2 & 1 & 2 & 2 & 1 \\
\hline 11 & 2 & 2 & 1 & 1 & 1 & 1 \\
\hline 12 & 1 & 1 & 1 & 1 & 2 & 1 \\
\hline \multicolumn{7}{|c|}{ Downstream gate } \\
\hline 1 & 2 & 2 & 1 & 2 & 2 & 1 \\
\hline 2 & 2 & 2 & 1 & 2 & 2 & 1 \\
\hline 3 & 1 & 2 & 1 & 2 & 2 & 1 \\
\hline 4 & 2 & 2 & 1 & 1 & 2 & 1 \\
\hline 5 & 2 & 2 & 1 & 2 & 2 & 1 \\
\hline 6 & 2 & 2 & 1 & 2 & 2 & 1 \\
\hline 7 & 1 & 2 & 1 & 2 & 2 & 1 \\
\hline 8 & 1 & 2 & 1 & 1 & 2 & 1 \\
\hline 9 & 1 & 2 & 1 & 1 & 2 & 1 \\
\hline 10 & 2 & 2 & 1 & 1 & 1 & 1 \\
\hline 11 & 1 & 2 & 2 & 1 & 1 & 1 \\
\hline 12 & 2 & 2 & 1 & 1 & 2 & 1 \\
\hline
\end{tabular}

$4.22 t^{1.13}$ after inspections in years 1998 and 2008, respectively.

With the parameters of the thickness loss due to corrosion estimated at any point in time, it is a straightforward process to update the reliability, the hazard functions, and the economic analysis for the miter gate. The original model greatly overestimated the corrosion effect. While the new analysis is based on visual inspection data and conservative assumptions, the results are much better than if the information had not been used at all.

\section{Reliability analysis of Lock and Dam 27}

Lock and Dam 27 (Fig. 12) is located near the junctions of the Illinois, Missouri, and Mississippi Rivers

Table 6

Corrosion loss estimate for Lock and Dam 12 based on original deterioration models and inspection results

\begin{tabular}{lllllll}
\hline Corrosion loss & $\begin{array}{l}\text { Atmospheric } \\
\text { zone model }\end{array}$ & $\begin{array}{l}\text { Splash-zone } \\
\text { model }\end{array}$ & \multicolumn{5}{l}{ Updating method } \\
\cline { 3 - 7 } & & & $\mathrm{A}$ & $\mathrm{B}$ & $\mathrm{C}$ & $\mathrm{D}$ \\
\hline Mean $(\mu \mathrm{m})$ & 298 & 5080 & 250 & 285 & 314 & 349 \\
Standard & 197 & 1301 & 151 & 151 & 150 & 150 \\
deviation $(\mu \mathrm{m})$ & & & & & & \\
\hline
\end{tabular}

(Fig. 1) and falls under the St. Louis District of the Corps of Engineers. The miter gates for this lock are framed horizontally and have 14 main support girders as shown in Fig. 13. Given the heights of the upper and lower pools, girders 1-6 are considered in the atmospheric zone, girders $7-10$ in the splash zone, and girders 11-14 in the submerged zone. The miter gate is in the open configuration.

The reliability analysis is based on the fatigue capacity of the most critical weld on the miter gate.

Table 7

Characteristics of the four updating methods A-D

Characteristic of updating method

Updating method

Requires quantification of corrosion loss A $\quad$ B $\quad$ C D (Table 4)

Segment-based inspection required

Bayesian updating — considers prior

information

Can update reliability of structure at point in time

Can update deterioration model and reliability over time

Can track progress through a condition state

Applicable to system reliability analysis 


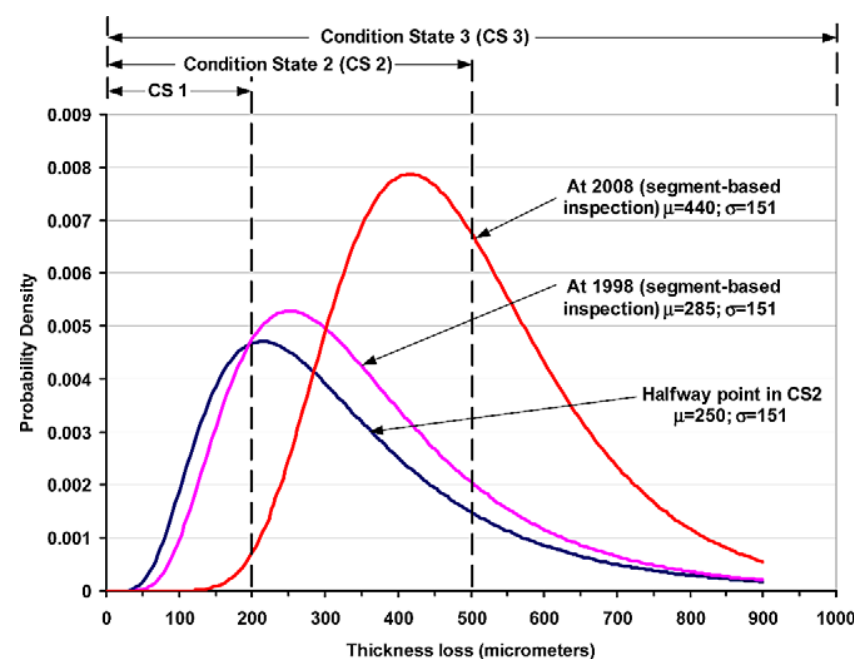

Fig. 10. Progression of miter gate through condition state 2 for corrosion based on inspection results.

The moment capacity of the corroding girders was analyzed, but was considered negligible in comparison to the fatigue. The critical welds were determined to be the category $\mathrm{E}$ welded joints between the tension flange of the horizontal girders and the diaphragm flanges. Using a Von Mises failure criterion, the stress range on the weld $\left(F_{\text {weld }}\right)$ is a function of the stresses on the girder $\left(F_{\text {girder }}\right)$ and its perpendicular diaphragm $\left(F_{\text {diaphragm }}\right)$ :

$F_{\text {weld }}=k_{\mathrm{s}} \sqrt{F_{\text {girder }}^{2}+F_{\text {girder }} F_{\text {diaphragm }}+F_{\text {diaphragm }}^{2}}$

where $k_{\mathrm{s}}$ is a modeling uncertainty factor described by the lognormal distribution as LN[1.02,0.10] [26]. The girder stress $\left(F_{\text {girder }}\right)$ represents the combined effect of the bending stress in the girder caused by the hydraulic loading and an axial stress developed as the angled miter gate is treated as a three-hinge arch. The stress in

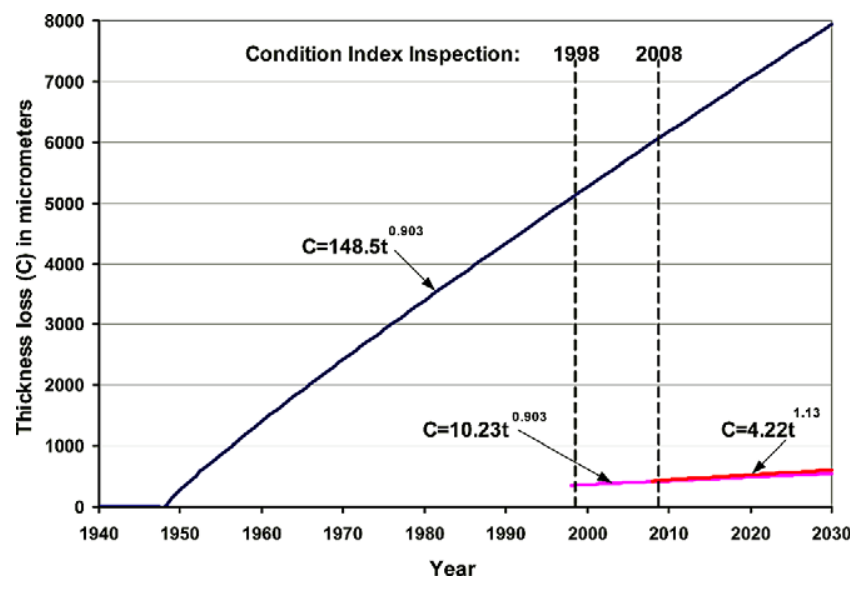

Fig. 11. Updated deterioration models based on condition index inspections in 1998 and 2008 [3].

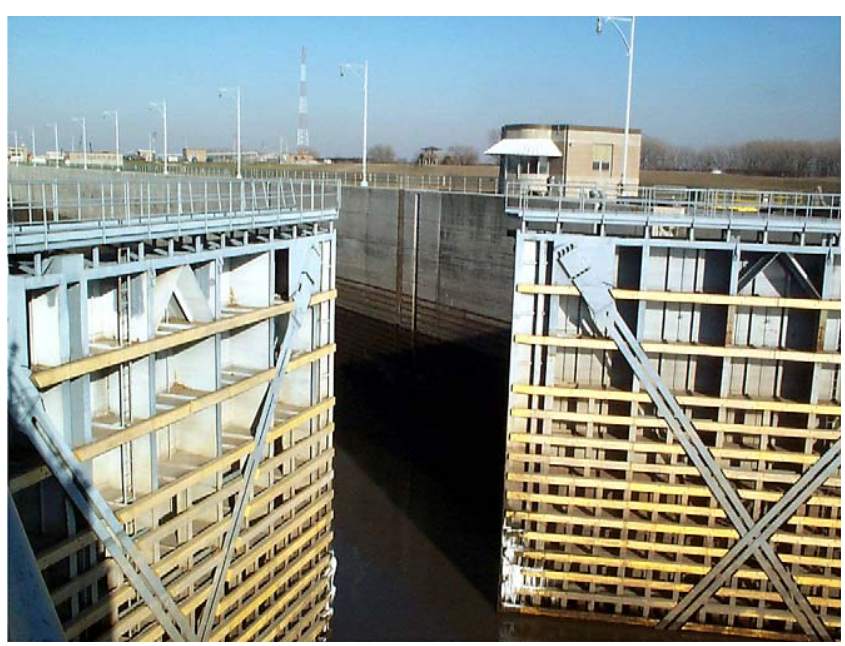

Fig. 12. Photograph of the miter gate on Lock and Dam 27 [8].

the diaphragm is computed as

$F_{\text {diaphragm }}=\alpha F_{\text {girder }}$

where $\alpha=1.49$ is an index determined by a combination of finite element analysis and strain gage testing
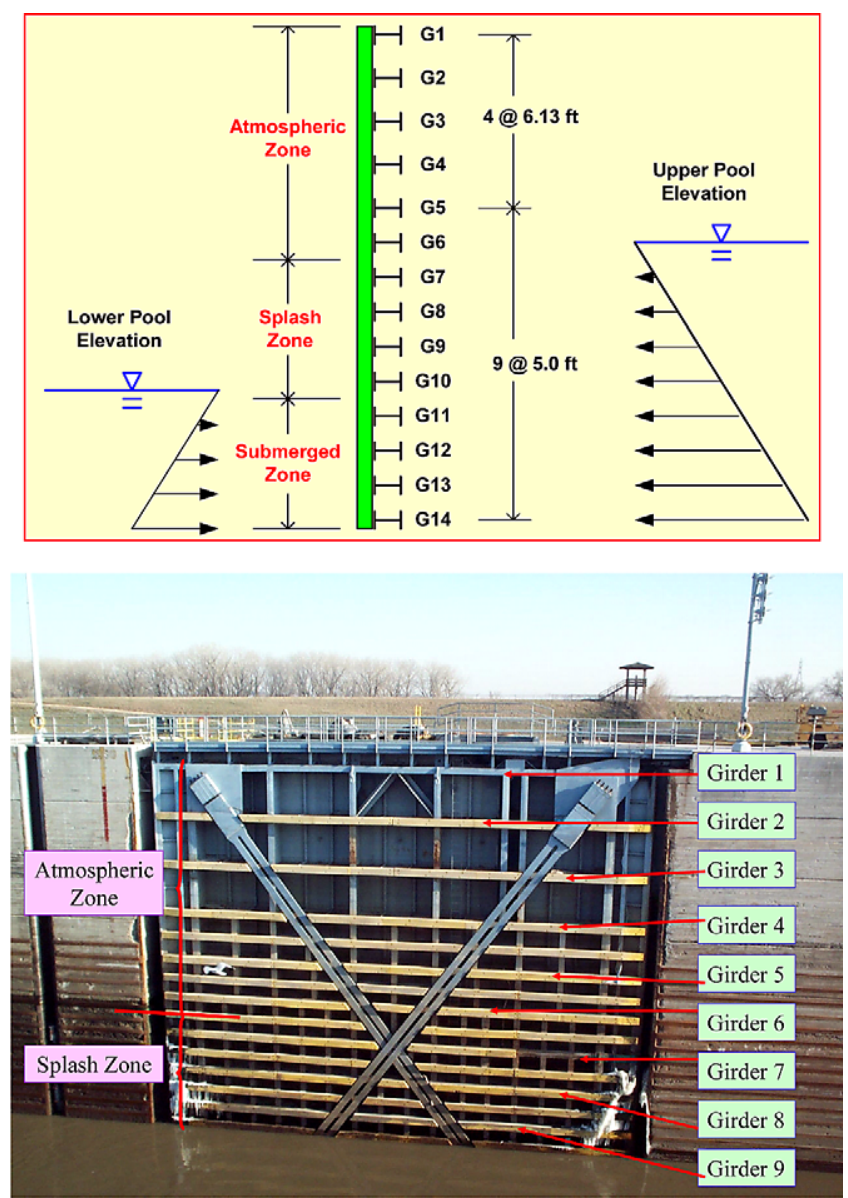

Fig. 13. Location of horizontal girders and environmental zones of the miter gate on Lock and Dam 27 [8]. 
of the miter gate [26]. The girders are corroding in a manner similar to Lock and Dam 12 and the section loss results in an increased girder stress that affects the fatigue life.

The fatigue capacity of the critical weld was determined using the characteristic $S-N$ approach based on fatigue test data ( $S-N$ curves) and Miner's rule, which assumes accumulated fatigue damage is linear. The fatigue capacity expressed as number of cycles $N$ is calculated as

$\log N=A-m \log F_{\text {weld }}+\varepsilon$

where $A=9.29$ and $m=3.09$ are fatigue parameters based on experimental data associated with category $\mathrm{E}$ welds [16], $F_{\text {weld }}$ is the stress range within a cycle on the critical weld and $\varepsilon$ is a model uncertainty factor with parameters $\mathrm{N}[0,0.1]$. The fatigue demand is the number of load cycles represented by the number of times the water in the lock chamber is raised and lowered. Fig. 14 shows the number of lockages, which represents that amount of barge traffic that passes through a lock and is obtained through the USACE Lock Performance Monitoring System [28]. For the future, it was estimated that lockages will increase by $1 \%$ every year. Because of two-way river traffic and multiple tows, a lockage does not necessarily correspond to a stress cycle. To make the conversion, a random variable $k_{\mathrm{c}}$, $\mathrm{N}[0.772,0.031]$, representing the ratio of the number of stress cycles to the number of lockages is used.

The analysis was performed for each year. Because the stresses were different every year, the percentage of fatigue life that was used by the load cycles in a given year was computed. A cumulative total of the fatigue damage was maintained and failure occurred when the accumulated damage $D$ exceeded the random damage life of the weld $\Delta$ which has the mean of 1.0 and a standard deviation of $0.30, \mathrm{~N}[1.0,0.30]$. This randomness in $\Delta$ accounts for variations in Miner's rule [16].

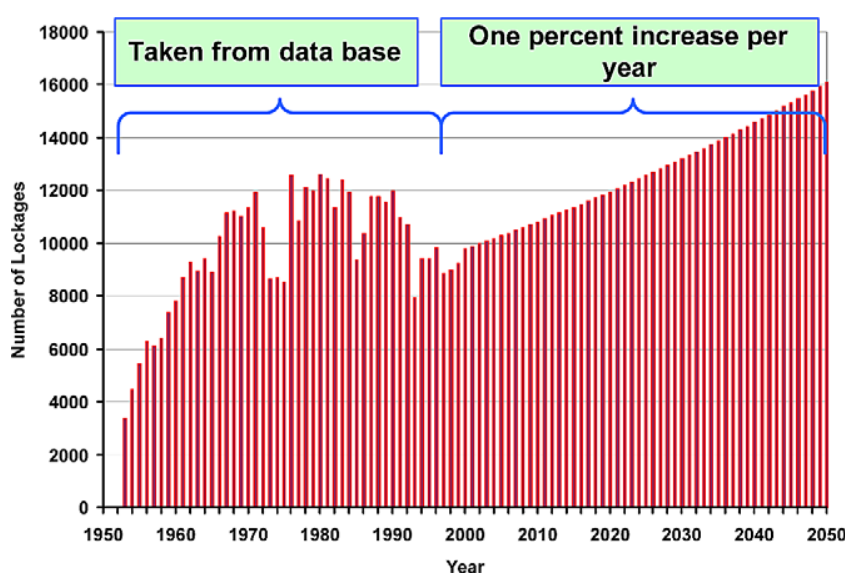

Fig. 14. Number of lockages on Lock and Dam 27; the future projection is $1 \%$ per year [4].
The miter gate reliability is defined as the probability that the structure survives:

$\left.P \quad D=\sum_{j=1}^{k} \frac{N_{t, j}}{N_{j}}<\Delta\right)($

where $N_{t, j}$ is the actual number of cycles in a given year and $N_{j}$ is the allowable fatigue life determined by Eq. (8) using the stress range on the weld, $F_{\text {weld }}$, for that year. The random variables associated with this analysis are shown in Table 8 and the point-in-time probabilities of failure associated with three girders from the Lock and Dam 27 miter gate are shown in Fig. 15. Girder 13 is in the submerged zone where the corrosion is much less and the stress range through the raising-lowering cycle is small. Both girders 8 and 10 are in the splash zone where corrosion is greatest, but girder 10 is at a lower elevation and experiences a greater stress range and is, therefore, the most critical girder for fatigue damage.

The graph for girder 10 (Fig. 15) represents the cumulative probability of failure, $P_{\mathrm{f}}(t)$. The reliability function $R(t)$ is equal to $1-P_{\mathrm{f}}(t)$. The PDF for the failure of the structure can be computed as

$p_{\mathrm{f}}(t)=\frac{\mathrm{d} P_{\mathrm{f}}}{\mathrm{d} t}$

and the hazard function $h(t)$ that represents the probability of failure over a specific time interval $(t, t+\mathrm{d} t)$, given that the structure has not already failed in $(0, t)$, is computed as

$h(t)=\frac{p_{\mathrm{f}}(t)}{R(t)}$

Fig. 16 shows the hazard function $h(t)$ for girder 10 . The hazard function using raw data is obtained by numerically differentiating $p_{\mathrm{f}}(t)$ and provides a very jagged hazard curve. The data can be fitted to a Weibull distribution [16] to produce a smooth, constantly increasing hazard curve as shown in Fig. 16.

The hazard function is then used to conduct a yearby-year cost-benefit analysis to determine at what point in time the major rehabilitation is economically justified. The National Economic Development (NED) benefits are based on reduced transportation costs and fewer future maintenance costs. The NED costs include the cost of the rehabilitation project, the potential detrimental impacts to navigation while any rehabilitation is being implemented, and future maintenance costs associated with the rehabilitation. The consequences of rehabilitation are estimated for a range of possible consequences of unsatisfactory component performance [26]. Table 9 shows the consequences and their associated costs and probabilities for Lock and Dam 27. In sum, USACE is one of the few organizations that are 
Table 8

Random variables used in reliability analysis of horizontal girders on Lock and Dam 27 [16,26]

\begin{tabular}{|c|c|c|c|c|}
\hline Random variable & Symbol & Distribution type & Mean $(\mu)$ & Standard deviation $(\sigma)$ \\
\hline Lower pool elevation $(1953-1962)^{a}$ & $\mathrm{El}_{\text {lower }}$ & Truncated normal $^{\mathrm{b}}$ & $118.8 \mathrm{~m}(389.6 \mathrm{ft})$ & $2.57 \mathrm{~m}(8.42 \mathrm{ft})$ \\
\hline Lower pool elevation (1963-2050) & $\mathrm{El}_{\text {lower }}$ & Truncated normal $^{\mathrm{c}}$ & $120.0 \mathrm{~m}(393.6 \mathrm{ft})$ & $2.83 \mathrm{~m}(9.27 \mathrm{ft})$ \\
\hline Upper pool elevation (1953-1962) & $\mathrm{El}_{\text {upper }}$ & Truncated normal $^{\mathrm{d}}$ & $121.7 \mathrm{~m} \mathrm{(399.3 \textrm {ft } )}$ & $2.01 \mathrm{~m}(6.59 \mathrm{ft})$ \\
\hline Upper pool elevation (1963-2050) & $\mathrm{El}_{\text {upper }}$ & Truncated normal ${ }^{\mathrm{e}}$ & $123.4 \mathrm{~m}(404.8 \mathrm{ft})$ & $1.86 \mathrm{~m}(6.09 \mathrm{ft})$ \\
\hline Cycles per lockage & $k_{\mathrm{c}}$ & Lognormal & 0.772 & 0.031 \\
\hline Stress model uncertainty factor & $k_{\mathrm{s}}$ & Lognormal & 1.02 & 0.10 \\
\hline Damage accumulation & $\Delta$ & Lognormal & 1.0 & 0.30 \\
\hline Fatigue uncertainty & $\varepsilon_{\mathrm{f}}$ & Normal & 0.0 & 0.10 \\
\hline Corrosion uncertainty: atmospheric zone & $\varepsilon_{\mathrm{c}-\text { atmos }}$ & Normal & 0.0 & 0.219 \\
\hline Corrosion uncertainty: splash zone & $\varepsilon_{\text {c-splash }}$ & Normal & 0.0 & 0.099 \\
\hline
\end{tabular}

\footnotetext{
${ }^{a}$ A downstream dam was constructed in 1963 that changed the water elevations within Lock and Dam 27.

b Truncated values: minimum $115.0 \mathrm{~m}(377.4 \mathrm{ft})$; maximum $129.1 \mathrm{~m}(423.6 \mathrm{ft})$.

${ }^{\mathrm{c}}$ Truncated values: minimum $114.5 \mathrm{~m}(375.6 \mathrm{ft})$; maximum $131.9 \mathrm{~m}(432.8 \mathrm{ft})$.

${ }^{\mathrm{d}}$ Truncated values: minimum $118.5 \mathrm{~m}(388.9 \mathrm{ft})$; maximum $130.5 \mathrm{~m}(428.3 \mathrm{ft})$.

e Truncated values: minimum $120.3 \mathrm{~m}(394.7 \mathrm{ft})$; maximum $133.3 \mathrm{~m}(437.2 \mathrm{ft})$.
}

using structural reliability methods to make real economic decisions on construction projects.

\section{Condition state definition for miter gate fatigue}

Reliability with respect to fatigue is probably the most difficult to update from a visual inspection. There is no evidence of fatigue damage until a surface crack appears that is visible to the human eye. In virtually every case, it occurs late in the fatigue life of the structure and in some cases this is too late. Most current visual inspection systems do not expect a detailed assessment of fatigue damage. The USACE CI evaluation is based solely on the number of cracks encountered on the girders, plates, and intercostals. The size and location are recorded but are not part of the condition rating [9]. The limiting values for the number of cracks on the girders, intercostals, and skin plate are $X_{\operatorname{max~G}}=1, X_{\max I}=10$, and $X_{\operatorname{max~S}}=10$. The total CI rating is the worst individual score, i.e.,

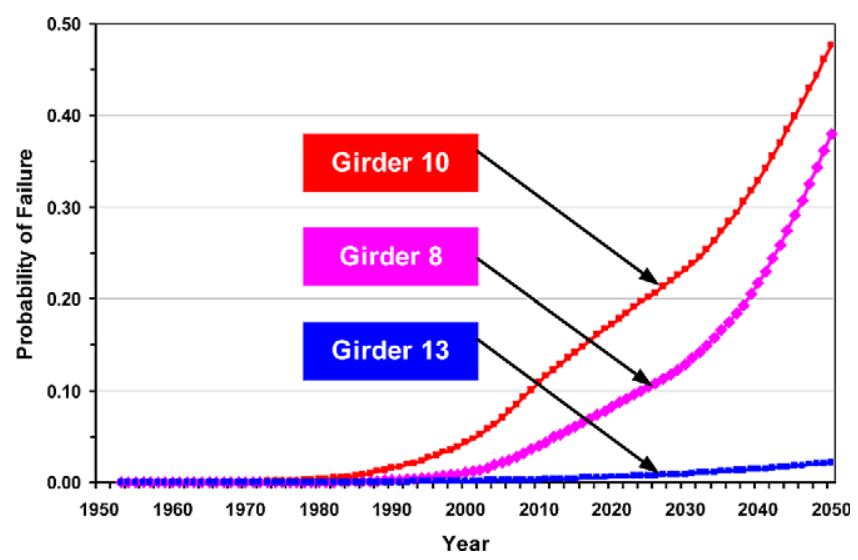

Fig. 15. Probability of failure of girders 8,10 , and 13 on Lock and Dam 27 based on fatigue damage.
$\mathrm{CI}=\min \left(\mathrm{CI}_{\mathrm{G}}, \mathrm{CI}_{\mathrm{I}}, \mathrm{CI}_{\mathrm{S}}\right)$, where $\mathrm{CI}_{X}=100(0.4)^{X / X_{\max }}$. A single crack on a girder automatically constitutes a rating of 40 and triggers an economic analysis of repair alternatives. Managing agencies are understandably reluctant to ask an inspector to assess fatigue damage where a microscopic crack on a fracture critical member may be far more serious than a large crack on a highly redundant member. The absence of a crack provides little useful information for updating.

Nevertheless, life-cycle planning is based on an expected deterioration due to fatigue. In the original reliability analysis, there is a time where cracks are expected to appear based on the deterioration model. The information on those observed cracks or the absence of cracks when they were expected should be used to the maximum extent possible.

While there are many NDE methods that are commonly used to detect fatigue cracks such as dye penetrant, ultrasonics, magnetic particle, eddy current, or radiographic inspections, most surface flaws in miter

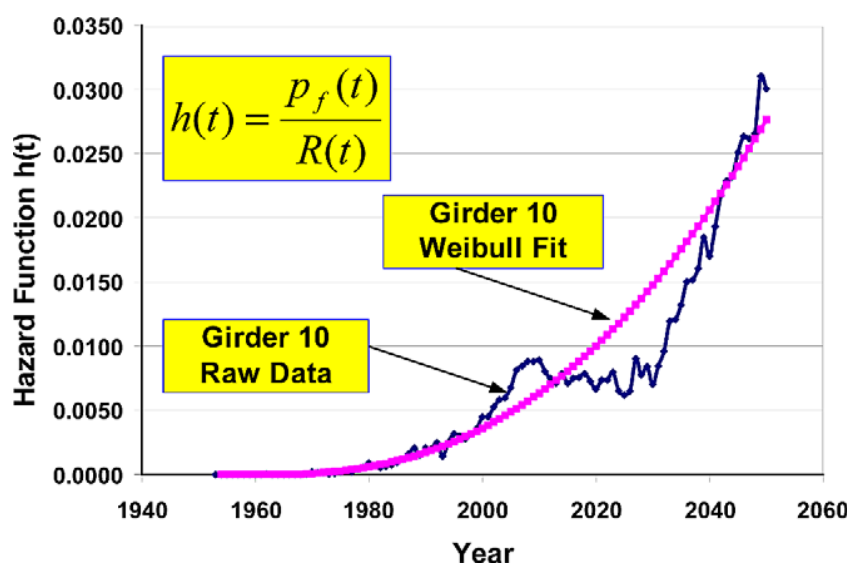

Fig. 16. Hazard function for girder 10 on Lock and Dam 27 based on fatigue damage. 
Table 9

Navigation consequences, costs, and associated probabilities for miter gate rehabilitation on Lock and Dam 27

\begin{tabular}{clllr}
\hline $\begin{array}{c}\text { Year Hazard } \\
\text { rate }\end{array}$ & $\begin{array}{l}\text { Economic } \\
\text { impact }\end{array}$ & $\begin{array}{l}\text { Conditional } \\
\text { probability }\end{array}$ & $\begin{array}{l}\text { Navigation } \\
\text { consequence }\end{array}$ & $\begin{array}{l}\text { Repair } \\
\text { cost, US\$ }\end{array}$ \\
\hline 20010.0305 & Low & 0.70 & $\begin{array}{l}\text { 10 day main } \\
\text { lock closure }\end{array}$ & 750,000 \\
& Medium & 0.20 & $\begin{array}{l}\text { 30 day main } \\
\text { lock closure }\end{array}$ & $2,250,000$ \\
0.0305 & High & 0.10 & $\begin{array}{l}\text { 60 day main } \\
\text { lock closure }\end{array}$ & $4,500,000$ \\
0.0305 & & & & \\
\hline
\end{tabular}

gates are detected visually by field inspectors and are described by the length of the surface crack [11]. A visual inspection is less costly, less time consuming, and can cover a large area quickly.

The characteristic $S-N$ approach is widely accepted and recommended for reliability-based fatigue design [15]. The only way to update the reliability based on the observed crack size is to either start with or convert to a crack growth deterioration model rather than the characteristic $S-N$ approach currently used. The most widely used crack growth model is the Paris law [17]

$\frac{\mathrm{d} a}{\mathrm{~d} N}=C(\Delta K)^{m}$

where $C$ and $m$ are experimentally derived parameters, $a$ is the crack depth, $N$ is the number of cycles, and $\Delta K$ is the stress intensity range.

McAllister and Ellingwood [13] developed a crack growth model specifically for welded steel miter gates that relates the length of an observed surface crack to the number of stress cycles. Based on the detailed analyses of two miter gates, the model used $C=2.4 \times 10^{-10}, m=3$, and

$\Delta K=Y F_{\text {weld }} \sqrt{\pi a}$

where $a$ is the drack depth, $Y$ is a geometry factor dependent on $a$ and stress concentrations, and $F_{\text {weld }}$ is the stress range on the critical weld (Eq. (6)). The finite element analyses revealed a stress concentration factor of 3.5. The model uncertainty was incorporated into lognormally distributed random variable $X(N)$ with a mean value of 1.0 and a coefficient of variation that varied over the number of cycles. The crack depth was found to be one-sixth of the crack length and failure occurred when the crack depth $a$ exceeded the thickness of the girder flange.

A crack growth model assumes that all welds have some inherent flaw and an initial flaw size must be assumed. The initial flaw was assumed to have exponential distribution

$f_{\text {initial }}(a)=\lambda \mathrm{e}^{-\lambda a}$

where $\lambda=0.16 \mathrm{~mm}^{-1}\left(0.0064 \mathrm{in.}^{-1}\right)$ [18]. This is the most uncertain variable in the analysis. McAllister and Ellingwood [13] also used more conservative values of initial flaw size such as $a=0.5 \mathrm{~mm}(0.02 \mathrm{in}$.) to coincide with the largest flaw size that an inspector might reasonably be expected to miss in an initial inspection.

There is not a necessarily good correlation between the $S-N$ deterioration model and the crack growth model despite some common parameters such as the stress field and the number of cycles. Fig. 17 compares the reliability index $\beta$ over time for the miter gate on Lock and Dam 27 using the original $S-N$ model and the crack growth model varying both the stress concentration factor and the initial flaw size. The simulation package @RISK [14] was used for the reliability analysis. An individual analyst must choose the most appropriate models for initial analysis and design, but any of these models can be updated once a crack is observed.

\section{Condition state definition for miter gate fatigue}

The definition of a fatigue condition state should be based on what an inspector should be expected to observe. McAllister and Ellingwood [12] incorporated the following visual detection capabilities for surface cracks: very good $3.0 \mathrm{~mm}(0.12 \mathrm{in}$.); good $9.0 \mathrm{~mm}(0.36$ in.); poor $18.0 \mathrm{~mm}$ (0.75 in.); and very poor $>36 \mathrm{~mm}$ (>1.5 in.). Their interviews with USACE inspectors indicate that field detection of surface crack lengths less than $3-6 \mathrm{~mm}(1 / 8-1 / 4 \mathrm{in}$.) is very good. Table 10 proposes condition state definitions for fatigue. The condition states do not have probabilistic distributions as the reliability is computed using a crack growth model where the observed crack is the basis for the initial flaw size. As previously indicated, the condition state is entered at its midpoint and transitions linearly through the condition state based on the predictions of the crack growth model.

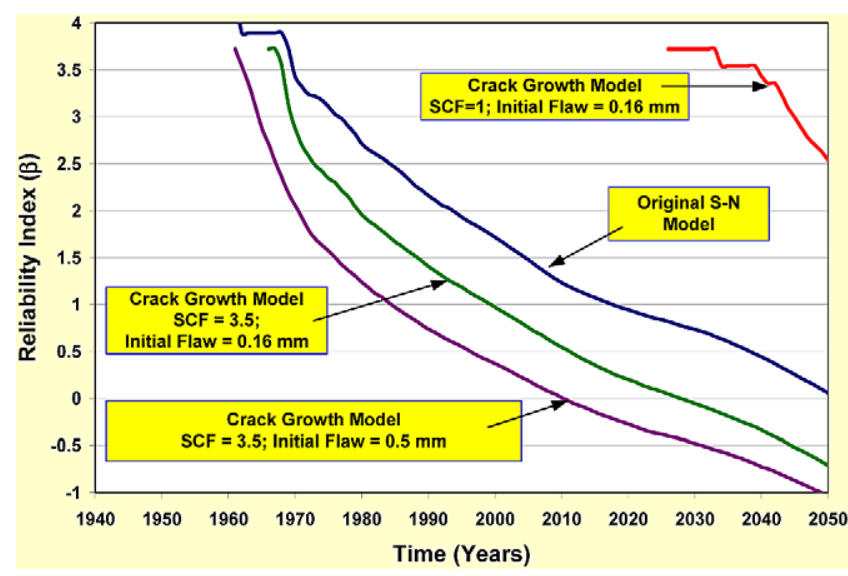

Fig. 17. Reliability index $(\beta)$ for girder 10 fatigue deterioration using the characteristic $S-N$ model and several crack growth models. 
Table 10

Proposed condition state definitions for fatigue based on visual inspection

\begin{tabular}{lll}
\hline Rating & Description & Initial flaw size $(a)^{\text {a }}$ \\
\hline 1 & No crack observed, surface length $<3.2 \mathrm{~mm}(1 / 8 \mathrm{in} .)^{\mathrm{b}}$ & $0.53 \mathrm{~mm}(0.021 \mathrm{in})$. \\
2 & Surface crack observed, $3.2 \mathrm{~mm}(1 / 8 \mathrm{in}$.$) \leq surface length <6.4 \mathrm{~mm}(1 / 4 \mathrm{in})$. & $0.80 \mathrm{~mm}(0.031 \mathrm{in})$. \\
3 & Surface crack observed, $6.4 \mathrm{~mm}(1 / 4 \mathrm{in}$.$) \leq surface length <12.7 \mathrm{~mm}(1 / 2 \mathrm{in})$. & $1.6 \mathrm{~mm}(0.063 \mathrm{in})$. \\
4 & Surface crack observed, $12.7 \mathrm{~mm}(1 / 2 \mathrm{in}$.$) \leq surface length \leq 25.4 \mathrm{~mm}(1 \mathrm{in})$. & $3.2 \mathrm{~mm}(0.13 \mathrm{in})$. \\
5 & Surface crack observed, surface length $>25.4 \mathrm{~mm}(1 \mathrm{in})$. & Actual measured length \\
\hline
\end{tabular}

${ }^{a}$ Initial flaw size for crack growth model is the assumed crack depth (a) based on entering the condition state in the middle and the crack depth being one-sixth of the surface crack length.

${ }^{b}$ When no crack is observed, it is assumed that the largest surface crack that could go undetected is $6.4 \mathrm{~mm}(1 / 4$ in.) for a very experienced inspector, $12.7 \mathrm{~mm}(1 / 2 \mathrm{in}$.) for an experienced inspector, and $25.4 \mathrm{~mm}(1 \mathrm{in}$.) for an inexperienced inspector.

Miter gates have proven to be highly redundant structures. Inspections have revealed large fatigue cracks on girders that have no noticeable effect on the performance of the structure. McAllister [11] treated fatigue cracks as a serviceability limit state. Without the danger of fracture critical members, this is an ideal application for having inspectors provide a more detailed classification for fatigue cracks.

\section{Miter gate fatigue updating}

There are two possible outcomes from a visual inspection: either a crack is observed or it is not. There is little chance of a false positive and the best information comes from an observed crack. Within the uncertainty of the inspectors' visual ability, an updated initial flaw size is produced and remaining fatigue life can be more accurately estimated. Unfortunately, a visual crack often indicates that there is very little fatigue life remaining.

Table 11 shows the results of hypothetical fatigue inspections conducted every 2 years for the miter gate

Table 11

Hypothetical CI inspection results for fatigue

\begin{tabular}{ll}
\hline Year & Condition state \\
\hline 1996 & 1 \\
1998 & 1 \\
2000 & 1 \\
2002 & 1 \\
2004 & 2 \\
2006 & 2 \\
2008 & 2 \\
2010 & 3 \\
2012 & 3 \\
2014 & 3 \\
2016 & 3 \\
2018 & 3 \\
2020 & 3 \\
2022 & 4 \\
2024 & 4 \\
2026 & 5 \\
2028 & 5 \\
2030 & 5 \\
\hline
\end{tabular}

on Lock and Dam 27. The first visible crack appears in 2004, which is earlier than the deterioration model predicted. Fig. 18 shows the reliability index, $\beta$, over time for both the original characteristic $S-N$ fatigue deterioration model and the updated crack growth deterioration model based on the $\mathrm{CI}$ inspection results. Once a crack appears, the crack growth model with stress concentration factor of 3.5 was used for the updating. The reliability is updated after every inspection, which is assumed to be conducted every 2 years. If the crack had been on a fracture critical member, it would never have been allowed to progress so far.

The more delicate situation is when the fatigue performance is better than the deterioration model predicts and no visible cracks ever appear. The CI rating for fatigue never changes from a condition state rating of 1 . It is also possible that a crack exists, but the inspector has not detected it. Fig. 19 shows the updated reliability for the miter gate when the inspectors are classified as very experienced, experienced, and inexperienced. The analysis is based on the assumption that a surface crack of 6,12 , and $25 \mathrm{~mm}(1 / 4,1 / 2$, and 1 in.), respectively, would not go undetected by the inspector. The crack growth model using a stress

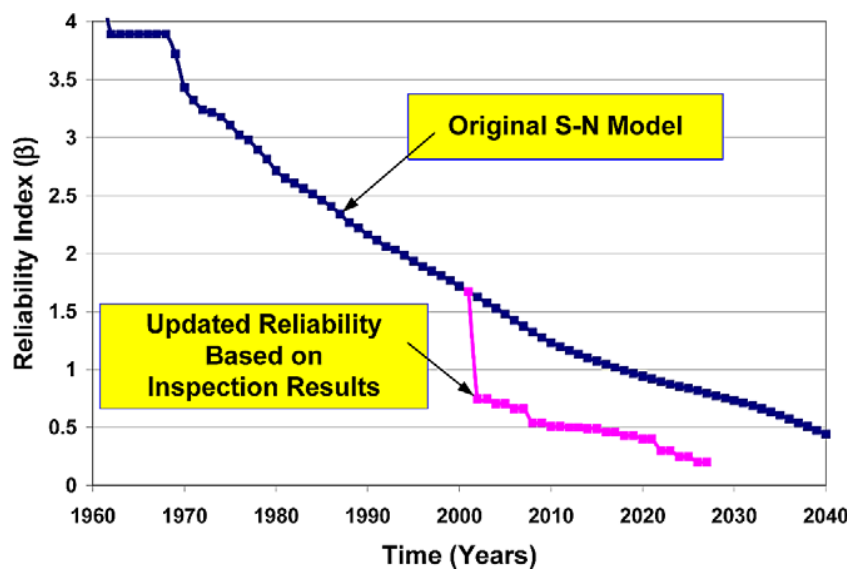

Fig. 18. Updated reliability index $(\beta)$ for girder 10 fatigue deterioration using inspection results and a crack growth model for observed cracks. 


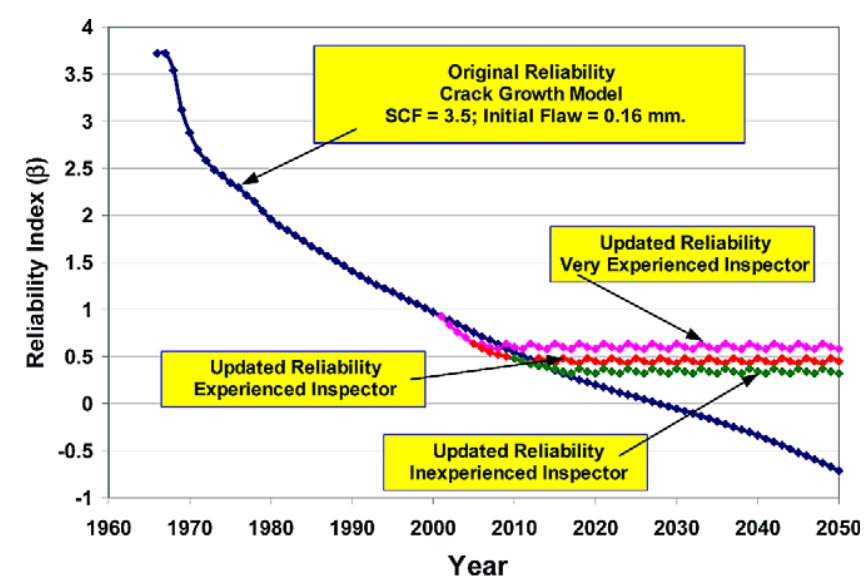

Fig. 19. Updated reliability index $(\beta)$ for girder 10 fatigue deterioration using inspection results when no cracks were found.

concentration factor of 3.5 and initial flaw size of 0.16 $\mathrm{mm}(0.0064 \mathrm{in}$.) was used for the initial model. The reliability curves flatten out as the original deterioration model has been invalidated. The reliability continues to deteriorate until a new inspection reveals that no cracks have appeared, but no new information is available to update the model and the analysis is based on the detection capability of the inspector. Still the absence of cracks when they were clearly expected provides some new information and it should be used to the extent possible.

The area of using visual inspection results for fatigue is the least developed and most open for new research. Another potential area of research is to establish correlation between visual inspection results and the corresponding NDE results for the same defect. This would strengthen the value and credibility of the visual inspections and allow visual and NDE inspections to be used in combination. The applicability is probably strongest for fatigue where both visual inspections and a variety of NDE techniques are commonly used.

\section{Conclusions}

As both reliability analyses and systematic inspection programs for the world's infrastructure gain increased usage and prominence, it becomes more important to use the information from routine visual inspections to update lifetime reliability assessments and resulting lifecycle inspection/repair strategies. The solution will not always be straightforward, but it would be wasteful not to use this existing information in a meaningful way. Most often some conservative assumptions will be necessary. Visual inspection data will never be a substitute for a well-designed NDE inspection for a particular defect, but it can certainly be a useful supplement.
This paper illustrated how the Army Corps of Engineers currently conducts reliability analyses on miter gates for locks and dams and then uses that information to make major rehabilitation decisions involving millions of dollars. It then showed how routine visual information obtained through established CI inspections could be used to update the reliability of miter gates that are deteriorating due to corrosion and fatigue. Some modifications to existing procedures are needed and are described in the form of quantified condition states and recorded location of damage, preferably using a segment-based inspection. Bayesian updating is useful when both the deterioration model and inspection results are uncertain. The key is finding a credible model that relates what the inspector sees to the actual limit state being examined.

The potential exists to follow this same procedure for any type of structure that is deteriorating over time, but it will take further research and a stronger correlation between what the inspector observes and the actual deterioration status of the structure. Engineers who develop inspection systems and those who perform reliability analyses need to communicate during the development process to maximize the effectiveness of inspection data.

\section{Acknowledgements}

The partial financial support of the US Army Corps of Engineers Construction Engineering Research Laboratory is gratefully acknowledged. The opinions and conclusions presented in this paper are those of the writers and do not necessarily reflect the views of the sponsoring organization.

\section{References}

[1] Albrecht P, Naeemi AH. Performance of weathering steel in bridges. National Cooperative Highway Research Program, Report 272, 1984.

[2] Ang AH-S, Tang WH. Probability concepts in engineering planning and design vol. I. Basic principles. New York: John Wiley and Sons; 1975 .

[3] Estes AC, Frangopol DM, Foltz SD. Using visual inspection results to update reliability analyses of highway bridges and river lock structures. ICOSSAR'01. Proceedings of the 8th International Conference on Structural Safety and Reliability, Newport Beach, CA, June 17-22, 2001. Sweets \& Zeitlinger Publishers; 2002 [on CD-ROM].

[4] Estes AC, Frangopol DM, Foltz SD. A time-dependent reliability approach to the life cycle analysis of miter gates on locks and dams. ASCE Structures Congress and Exposition, Denver, April 4-6. 2002 [on CD-ROM].

[5] Estes AC, Frangopol DM, Foltz SD. Updating the reliability of engineering structures using visual inspection results. In: Der Kiureghian A, Madanant S, Pestana JM, editors. Applications of statistics and probability in civil engineering. Rotterdam: 2, Millpress; 2003, p. 1087-92. 
[6] Estser AC, Frangopol DM. Updating bridge reliability based on BMS visual inspection results. Journal of Bridge Engineering, ASCE 2003;8(6):374-82.

[7] FHWA (Federal Highway Administration). Recording and coding guide for the structural inventory and appraisal of the nations' bridges. Report no. FHWA-ED-89-044, US Department of Transportation, Washington, DC, 1988.

[8] Gipson J, Estes AC. Reliability of miter gates on locks and dams. CE489 Independent study project, Department of Civil and Mechanical Engineering, US Military Academy, 2002. [Photographs were taken by J Gipson.]

[9] Greimann LF, Stecker JH, Rens K. Management system for miter gate locks. Technical report REMR-OM-08, US Army Construction Engineer Research Laboratory, Champaign, IL, 1990.

[10] Hearn G, Frangopol DM. Segment-based reporting for element level bridge inspection. Proceedings of the Fourth National Workshop on Bridge Research in Progress, Buffalo, NY. 1996, p. $33-8$.

[11] McAllister TP. Assessing the reliability of highly redundant welded steel frame structures. PhD thesis, Department of Civil Engineering, The Johns Hopkins University, Baltimore, MD, 1999.

[12] McAllister TP, Ellingwood BR. Reliability-based condition assessment of welded steel miter gate structures. Proceedings of the 8th ASCE Joint Specialty Conference on Probabilistic Mechanics and Structural Reliability, Notre Dame, IN, July 24-26. 2000 [PMC2000-025].

[13] McAllister TP, Ellingwood BR. Reliability-based condition assessment of welded steel miter gates with fatigue damage. ICOSSAR'01. Proceedings of the 8th International Conference on Structural Safety and Reliability, Newport Beach, CA, June 17-22, 2001. Sweets \& Zeitlinger Publishers; 2002 [on CDROM].

[14] Palisade. @RISK advanced risk analysis for spreadsheets. Newfield (NY): Palisade Corporation; 2002.

[15] Melchers RE. Structural reliability analysis and prediction, 2nd ed. Chichester (UK): John Wiley and Sons; 1999.
[16] Padula J, Chasten C, Mosher R, Mlaker P, Brokaw J, Stough W. Reliability analysis of hydraulic steel structures with fatigue and corrosion degradation. Technical report ITL-94-3, US Army Corps of Engineers, Washington, DC, 1994.

[17] Paris PC, Ergodan F. A critical analysis of crack propagation laws. Transactions of ASME, Journal of Basic Engineering D $1963 ; 85(3)$.

[18] Provan JW. Probabilistic fracture mechanics and reliability. Hingham (MA): Kluwer Academic Publishers; 1987.

[19] Renn DP. Segment-based inspection for load rating within bridge management systems. Masters thesis, Department of Civil, Environmental, and Architectural Engineering, University of Colorado, Boulder, CO, 1995.

[20] Stecker JH, Greimann LF, Mellema M, Rens K, Foltz, SD. REMR management systems-navigation and flood control structures, condition rating procedures for lock and dam operating equipment. Technical report REMR-OM-19, US Army Corps of Engineers, Washington, DC, 1997.

[21] USACE, US Engineer Office. Report on corrosion test of metals in the Mississippi River. War Department, Corps of Engineers, US Army, Washington, DC, 1939.

[22] USACE (US Army Corps of Engineers). Lock gates and operating equipment. Engineering and design, Engineering manual EM 1110-2-2703, Washington, DC, 1994.

[23] USACE. Project operations: partners and support (work management guidance and procedures). Engineer pamphlet EP 11302-500, Washington, DC, 1996.

[24] USACE. Reliability analysis of miter gates lock and dam 12. Rock Island District, Rock Island, IL, 1997.

[25] USACE. Condition inspection summary report, Mississippi River lock and dam 12. Inspected by LDI and MVR, November 24, 1998, Dubuque, IA.

[26] USACE. Lock 27 major rehabilitation report, main chamber miter gate reliability analysis. St. Louis District, St. Louis, MO, 2002.

[27] USACE website, 2003. http://www.mvr.usace.army.mil/navdata.

[28] USACE website, 2003. http://www.iwr.usace.army.mil/ndc/ lpms/lpms.htm. 